\title{
Antiplatelet properties of Pim kinase inhibition are mediated through disruption of thromboxane $\mathbf{A} 2$ receptor signaling
}

\author{
Amanda J. Unsworth,,$^{1,2 *}$ Alexander P. Bye, ${ }^{1}$ Tanya Sage,${ }^{1}$ Renato S. Gaspar, ${ }^{1}$ \\ Nathan Eaton, ${ }^{3,4}$ Caleb Drew, ${ }^{3}$ Alexander Stainer, ${ }^{1}$ Neline Kriek, ${ }^{1}$ \\ Peter J. Volberding, ${ }^{3,4,5}$ James L. Hutchinson, ${ }^{6}$ Ryan Riley, ${ }^{2}$ Sarah Jones, ${ }^{2}$ \\ Stuart J. Mundell, ${ }^{6}$ Weiguo Cui, ${ }^{3,4,5}$ Hervé Falet $^{3,4}$ and Jonathan M. Gibbins ${ }^{1^{*}}$ \\ ${ }^{1}$ Institute for Cardiovascular and Metabolic Research, School of Biological Sciences, \\ University of Reading, Reading, UK; ${ }^{2}$ Department of Life Sciences, Faculty of Science and \\ Engineering, Manchester, Metropolitan University, Manchester, UK; ${ }^{3}$ Blood Research \\ Institute, Versiti, Milwaukee, WI, USA; ${ }^{4}$ Department of Cell Biology, Neurobiology, and \\ Anatomy, Medical College of Wisconsin, Milwaukee, WI, USA; ${ }^{5}$ Department of Microbiology \\ and Immunology, Medical College of Wisconsin. Milwaukee, WI, USA and ${ }^{6}$ School of \\ Physiology, Pharmacology \& Neuroscience, Bristol, UK
}

Haematologica 2021

Volume 106(7):1968-1978

${ }^{\star} A J U$ and JMG contributed equally to this work.

\section{ABSTRACT}

im kinases are upregulated in several forms of cancer, contributing to cell survival and tumor development, but their role in platelet function and thrombotic disease has not been explored. We report for the first time that Pim-1 kinase is expressed in human and mouse platelets. Genetic deletion or pharmacological inhibition of Pim kinase results in reduced thrombus formation but is not associated with impaired hemostasis. Attenuation of thrombus formation was found to be due to inhibition of the thromboxane A2 receptor as effects on platelet function were non-additive to inhibition caused by the cyclo-oxygenase inhibitor indomethacin or the thromboxane A2 receptor antagonist GR32191. Treatment with Pim kinase inhibitors caused reduced surface expression of the thromboxane A2 receptor and resulted in reduced responses to thromboxane A2 receptor agonists, indicating a role for Pim kinase in the regulation of thromboxane A2 receptor function. Our research identifies a novel, Pim kinase-dependent regulatory mechanism for the thromboxane A2 receptor and represents a new targeting strategy that is independent of cyclo-oxygenase- 1 inhibition or direct antagonism of the thromboxane A2 receptor that, while attenuating thrombosis, does not increase bleeding.

Received: April 1, 2019.

Accepted: May 27, 2020.

Pre-published: May 28, 2020.

https://doi.org/10.3324/haematol.2019.223529

(C)2021 Ferrata Storti Foundation

Material published in Haematologica is covered by copyright. All rights are reserved to the Ferrata Storti Foundation. Use of published material is allowed under the following terms and conditions:

https://creativecommons.org//icenses/by-nc/4.0/legalcode. Copies of published material are allowed for personal or internal use. Sharing published material for non-commercial purposes is subject to the following conditions:

https://creativecommons.org/licenses/by-nc/4.0/legalcode, sect. 3. Reproducing and sharing published material for commercial purposes is not allowed without permission in writing from the publisher.

\section{Introduction}

The family of Pim (proviral insertion in murine lymphoma) kinases, Pim-1, -2, and -3 , are highly homologous serine/threonine kinases that are widely expressed across several cell types, and are highly expressed in hematopoietic cells. Pim kinases are constitutively active and are linked with cancer progression, ${ }^{1,2}$ with overexpression and upregulation of Pim kinase activity associated with both hematologic cancers and solid tumors. They function by phosphorylating their target proteins on serine/threonine residues located within the common consensus sequence ARKRRHPS*GPPTA. ${ }^{1}$ A number of proteins that have important roles in the regulation of cellular proliferation and survival have been identified as phosphorylation targets of the Pim kinases. ${ }^{3.6}$ Expressed as a short $(32 \mathrm{kDa}$ ) or long (44 $\mathrm{kDa}$ ) variant, the longer variant of Pim-1 kinase, Pim-1L, kinase has also been found to regulate adenosine triphosphate-binding cassette drug transporters. ${ }^{7.9}$ Pim-1 phosphorylates both BCRP/ABCG2 and Pgp transporters enabling, through different mechanisms, the formation of drug efflux pumps. ${ }^{7,9}$

Pim kinases are highly expressed in hematopoietic cells where they are important for differentiation and development of blood cells and blood cell precursors including megakaryocytes ${ }^{10}$ and platelets. ${ }^{11}$ Whether Pim kinases are involved in the regulation of platelet function has not been explored. Analysis of the mouse 
megakaryocyte transcriptome database ${ }^{12}$ identified multiple tags for both Pim-1 and Pim-2 kinases and the mRNA transcripts for all three Pim kinases have been identified in the human platelet transcriptome..$^{13,14}$ Interestingly although triple knockout mice deficient in all three Pim kinase isoforms are viable, they have been shown to have altered hematopoiesis, but there is some dispute as to whether disruption of all three isoforms results in alteration of platelet count; ${ }^{10,11}$ however, platelet counts appear to be unaffected by alteration of Pim-1 expression levels in mice. $^{15,16}$

Platelets rely on $G$ protein-coupled receptors (GPCR) such as the thromboxane $\mathrm{A} 2$ receptor (TP $\alpha \mathrm{R}), \mathrm{ADP}$ receptors (P2Y1 and P2Y12) and the thrombin receptors (PAR1 and PAR4) to mediate platelet activation in response to vessel damage. All platelet GPCR are regulated in some way by receptor cycling/internalization from the platelet surface as well as desensitization. ${ }^{17} \mathrm{Pim}-1$ kinase has also been shown to have a role in the regulation of GPCR function, through modulation of surface levels of the CXCR4 receptor. ${ }^{18,19}$ Inhibition of Pim kinase prevents Pim kinase-dependent phosphorylation of CXCR4 at Ser339 and modification of the CXCR4 intracellular C terminal domain, resulting in reduced surface expression and signaling. In this study we report the presence of Pim-1 in human and mouse platelets, and reduced thrombosis in Pim-1 null mice, and following pharmacological inhibition of Pim kinase, but with no associated effect on hemostasis. We describe a novel mechanism of action by which Pim kinase inhibitors negatively regulate TP $\alpha$ R signaling.

\section{Methods}

Procedures and experiments using human blood were approved by the University of Reading Research Ethics Committee and protocols involving mice were performed according to the National Institutes of Health and Medical College of Wisconsin Institutional Animal Care and Use Committee guidelines and as following procedures approved by the University of Reading Research Ethics Committee.

Platelet isolation, thrombus formation assays, tail bleeding experiments, platelet function tests, aggregometry, granule secretion, flow cytometry, calcium imaging, immunoblotting, image analysis, statistical analyses and materials used are described in the Online Supplementary Methods.

\section{Results}

\section{Expression of Pim kinase in human and mouse platelets}

Pim kinases are highly expressed in hematopoietic cells. ${ }^{10,11}$ mRNA transcripts for all three Pim kinases have been identified in the human and mouse platelet transcriptomes $^{13,14}$ and HaemAtlas mRNA expression profiles in hematopoietic cells $\mathrm{s}^{20}$ show high expression of Pim-1 in megakaryocytes and moderate expression in platelets (Figure 1, Online Supplementary Figure S1). ${ }^{21}$ Western blot analysis of platelet lysates identified a protein band of 44 $\mathrm{kDa}$ apparent molecular mass in both human and mouse platelet lysates indicating the expression of the larger Pim-1 variant (Pim-1L). A protein band at $32 \mathrm{kDa}$ in mouse platelets also suggested expression of the smaller
Pim-1S. K562 and Jurkat cell lines were included as positive controls ${ }^{8,18,22}$ (Figure 1B).

\section{Reduced thrombus formation in Pim-1-deficient mice}

To determine whether Pim-1 plays a role in the regulation of platelet function and thrombosis, we measured the ability of Pim-1-deficient mouse platelets, taken from constitutive Pim-1-deficient mice, to form thrombi on collagen under arterial flow in vitro. Constitutive Pim $1^{-1}$ mice were as described previously 15,16 and global deletion of Pim-1 was confirmed by polymerase chain reaction analysis of genomic DNA (Online Supplementary Figure S2A). Whole blood from Pim-1\% or Pim-1 $1^{+/}$mice was perfused over collagen-coated $(100 \mu \mathrm{g} / \mathrm{mL})$ Vena8 biochips for $4 \mathrm{~min}$ at an arterial shear rate of $1000 \mathrm{~s}^{-1}$. Thrombus formation was significantly attenuated in blood from Pim- 1 - mice compared to controls, indicating that Pim-1 plays a positive role in the regulation of platelet function and thrombus formation on collagen (Figure 2A). Constitutive Pim-1\% mice show unaltered platelet counts and no difference in expression levels of major platelet adhesion receptors GPIb $\alpha$, GPIb $\beta$, GPIX, GPV, GPVI and integrins $\beta 1$ and $\beta 3$ was observed in $P$ im $-1 \%$ platelets compared to the levels in controls (Online Supplementary Figure $S 2 B)$. Interestingly, despite the reduced ability to form thrombi, Pim-1-deficient mice showed no alteration in hemostasis as tail bleeding was unaffected compared to that of littermate controls (Figure 2B).

\section{Pim kinase inhibitors reduce thrombus formation but do not disrupt hemostasis}

As genetic deletion of Pim-1 in mice resulted in reduced in vitro thrombus formation, we assessed the effects of the Pim kinase inhibitor AZD1208 $(100 \mu \mathrm{M})$ on thrombus formation in human whole blood. The effect of the Pim kinase inhibitor AZD1208 (100 $\mu \mathrm{M})$ on thrombus formation on collagen in human whole blood in vitro was also assessed. Human whole blood was pre-incubated with vehicle control or AZD1208 and perfused over collagencoated $(100 \mu \mathrm{g} / \mathrm{mL})$ Vena8 biochips at either an arterial shear rate $\left(20\right.$ dynes $/ \mathrm{cm}^{3}$ for $10 \mathrm{~min}$ ) or a pathological shear rate (135 dynes $/ \mathrm{cm}^{3}$ for $5 \mathrm{~min}$ ). Similarly to what had been observed in Pim-1-deficient mice, a reduction in thrombus formation and stability on collagen under flow in vitro was also observed following AZD1208 treatment in comparison to that seen in vehicle-treated controls under arterial shear conditions (Figure 2C). While thrombus size and stability appeared reduced at arterial flow rates, the early stages of thrombus formation, including initial adhesion, appeared unaffected by AZD1208 treatment. This was further supported by the lack of inhibition of platelet adhesion and spreading on collagen caused by AZD1208 under static conditions (Online Supplementary Figure S3), indicating that the initial adhesion to collagen is not affected by Pim kinase inhibition. Interestingly, enhanced inhibition of thrombus formation on collagen was observed following treatment with AZD1208 at pathological shear rates ( $80 \%$ inhibition) (Figure 2D) in comparison to the inhibition observed at an arterial shear rate ( $50 \%$ inhibition). In contrast to arterial and pathological shear rates, a slight (but not significant) reduction in thrombus formation was observed in AZD1208-treated platelets compared to vehicle-treated controls under venous shear conditions (Figure 2E). Inhibitor-treated platelets appeared to form 'woolly' or 
A
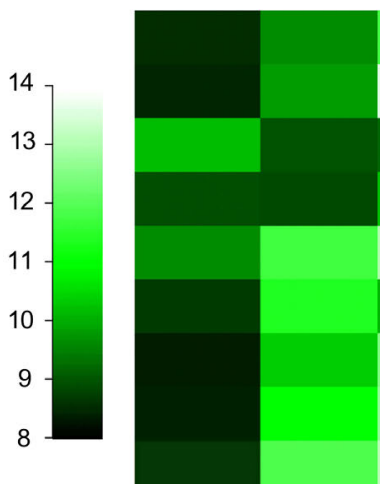

PIM3
MK

EB

HUVEC

CD14

CD66b

CD19

CD56

CD8

CD4
B

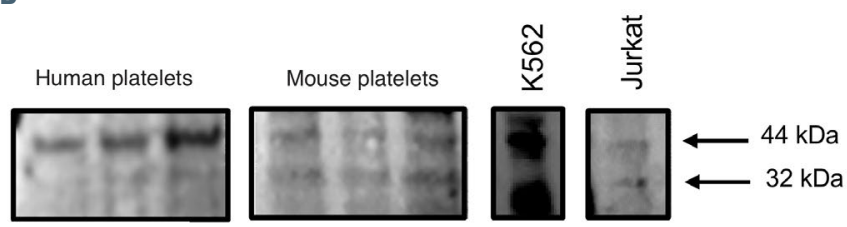

IB: Anti-Pim-1
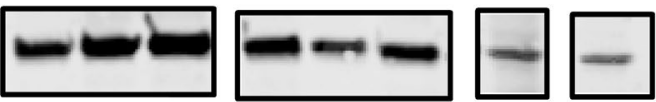

IB: Anti-Actin

Figure 1. Expression of Pim kinase in human and mouse platelets. (A) HaemAtlas analysis of Pim kinase mRNA expression levels. Pim kinase mRNA levels were quantified in human megakaryocytes and a range of blood cells by analysis of gene array data. Megakaryocytes (MK), human erythroblasts (EB), human umbilical vein endothelial cells (HUVEC), monocytes (CD14), granulocytes (CD66), mature B cells (CD19), natural killer cells (CD56), cytotoxic T cells (CD*) and helper T cells (CD4); 10+ (lighter colors) was deemed high expression. (B) Human and mouse washed platelets (three preparations) were lysed in SDS PAGE Laemmli sample buffer, separated on SDS PAGE gels and transferred to PVDF membranes before immunoblotting (IB) with anti-Pim-1 antibody. K562 and Jurkat cell lysates were included as positive controls. Actin was included as a loading control. Representative blots are shown.

'loose' aggregates compared to the aggregates formed in vehicle-treated controls, but no difference in fluorescence intensity of platelets adhered was observed. These findings indicate that Pim kinase inhibition does not significantly alter platelet adhesion and thrombus formation at low shear rates compared to the effects observed at higher shear rates. To examine whether Pim kinase inhibition could regulate thrombosis in vivo, we performed intravital microscopy following ferric-chloride-induced injury in mice pretreated with AZD1208 $(100 \mu \mathrm{M})$ or vehicle control (Figure 2F). As with in vitro thrombus formation, treatment with AZD1208 resulted in a dramatic attenuation in the ability of platelets to form thrombi in vivo, at the site of ferric-chloride-induced injury with significantly prolonged occlusion times observed in AZD1208-treated mice $(1463 \pm 37 \mathrm{~s})$ compared to those in vehicle-treated controls (697 $\pm 72 \mathrm{~s})$. This supports a role for Pim kinase in the positive regulation of platelet function, and the antiplatelet properties of Pim kinase inhibitors. Interestingly, despite the dramatic attenuation in the ability of platelets to form thrombi in vivo, as with genetic deletion, pharmacological inhibition of Pim kinase was not associated with altered hemostasis. Tail bleeding assays performed in mice indicated that treatment with AZD1208 (100 $\mu \mathrm{M})$ did not cause any significant increase in bleeding (Figure $2 \mathrm{G}$ ), suggesting that despite the observed inhibitory effect on thrombus formation, normal hemostasis is not compromised following inhibition or genetic deletion of Pim kinase.

\section{Pim kinase inhibitors reduce platelet aggregation}

To determine how Pim kinase plays a role in the regulation of platelet function, human washed platelets were pretreated for $10 \mathrm{~min}$ with a range of concentrations of the pan-Pim kinase inhibitor AZD1208 before stimulation with platelet agonists. As shown in Figure 3A-E pretreatment of platelets with AZD1208 inhibited aggregation stimulated by collagen $(1 \mu \mathrm{g} / \mathrm{mL})$ or the thromboxane A2 (TxA2) mimetic U46619 (0.3 $\mu \mathrm{M})$. A slight inhibition was also observed in CRP-XL stimulated platelets $(0.3 \mu \mathrm{g} / \mathrm{mL})$. In contrast no inhibition of thrombin- $(0.03$ $\mathrm{U} / \mathrm{mL})$ or ADP- $(10 \mu \mathrm{M})$ induced platelet aggregation was observed following treatment with increasing concentra- tions of AZD1208 (up to $10 \mu \mathrm{M}$ ). Treatment with four other structurally unrelated Pim kinase inhibitors, PIM447 (LGH-447), SGI-1776, SMI-4a and CX6258, inhibited platelet aggregation stimulated by either collagen or U46619 but not thrombin, recapitulating findings with AZD1208 and supporting a Pim kinase-dependent mode of action (Online Supplementary Figure S4).

Pim kinases have been shown previously to play important roles in cell survival as Pim-2 is known to phosphorylate and inactivate $\mathrm{Bcl}-2$-associated death promoter (BAD). ${ }^{23}$ Inhibition of Pim kinase enables activation of BAD and initiation of apoptosis. ${ }^{5}$ If Pim kinase inhibitors activate apoptosis in platelets, this could cause the observed reduction in aggregation. To investigate whether Pim kinase inhibition triggers apoptosis in platelets, phosphatidylserine exposure (a marker of membrane flippage) was determined by measuring annexin $\mathrm{V}$ binding by flow cytometry following treatment for $2 \mathrm{~h}$ with AZD1208 or the BCL-2 inhibitor ABT-263, an activator of apoptosis in platelets (Online Supplementary Figure $S 5 A)$. ABT-263 treatment caused an increase in annexin $\mathrm{V}$ binding but no difference was observed in AZD1208treated platelets compared to vehicle-treated controls over the same incubation time. Furthermore, caspase cleavage did not occur in platelets following $2 \mathrm{~h}$ of treatment with Pim kinase inhibitors: AZD1208 (10 $\mu \mathrm{M})$, SGI$1776(10 \mu \mathrm{M})$, SMI-4a $(30 \mu \mathrm{M})$ or CX6258 (10 $\mu \mathrm{M})$, but did occur following treatment with the BCL-2 inhibitor ABT-263 (Online Supplementary Figure S5B). Together these observations suggest that Pim kinase inhibition does not initiate platelet apoptosis.

\section{Pim kinase inhibitors reduce thromboxane A2-mediated $\alpha$-granule secretion and integrin activation}

Alpha granule secretion and activation of integrin $\alpha_{\mathrm{IIb}} \beta_{3}$ are critical events in platelet activation and aggregation. We investigated the effects of AZD1208 $(10 \mu \mathrm{M})$ on $\alpha$ granule secretion and $\alpha_{\mathrm{II}} \beta_{3}$ activation by measuring surface P-selectin exposure and fibrinogen binding, respectively. AZD1208 $(10 \mu \mathrm{M})$ inhibited $\alpha$-granule secretion and integrin activation evoked by collagen, CRP-XL and U46619 compared to the effects in vehicle-treated con- 
A (i)

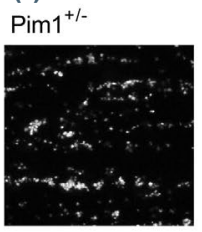

Pim1 ${ }^{-1}$

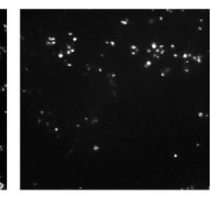

C (i)
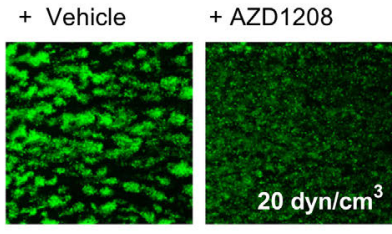

D (i)

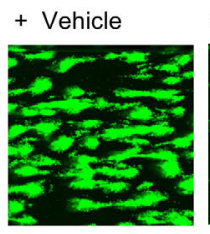

+ AZD1208

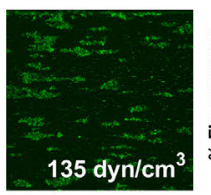

E (i)

+ Vehicle
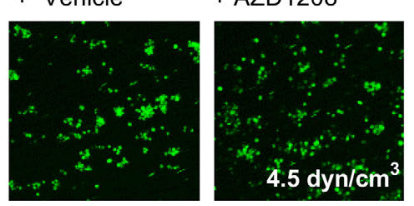

(ii)

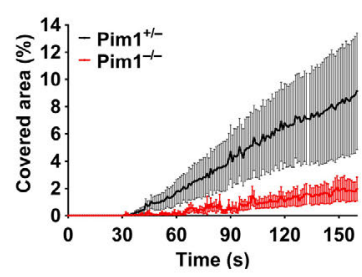

(ii)

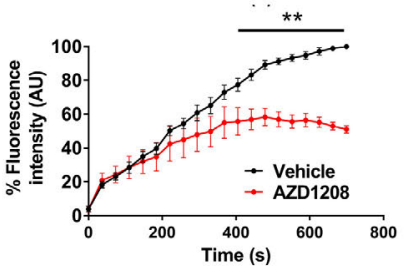

(ii)

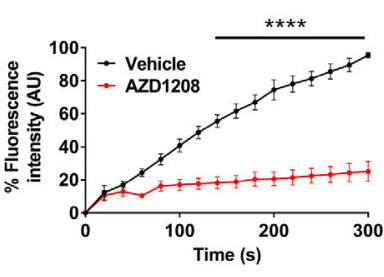

(ii)

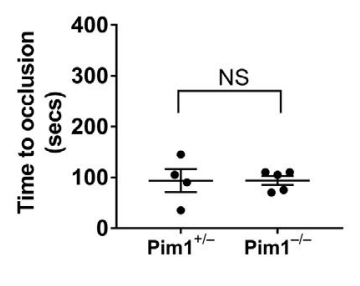

(i)
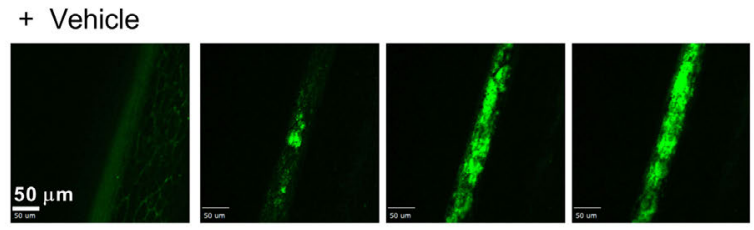

+ AZD1208
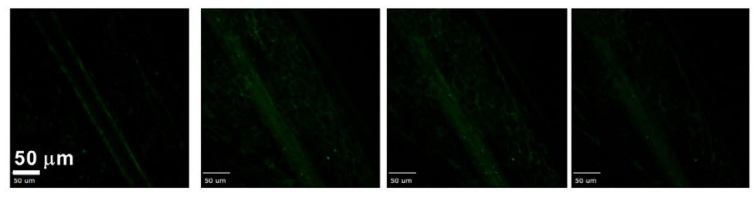

F (ii)

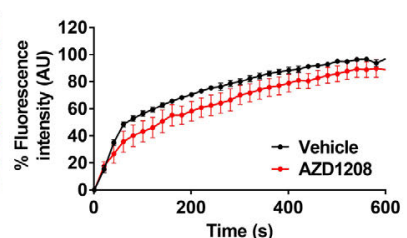

G

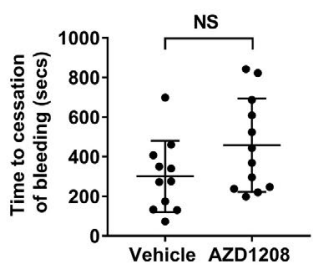

Figure 2. Genetic deletion and pharmacological inhibition of Pim-1 kinase attenuates thrombus formation on collagen, but does not cause bleeding. (A) DiOc6 loaded mouse whole blood from Pim $1^{+/}$(black) or Pim $1^{-1}$ (red) mice was perfused through collagen-coated $(100 \mu \mathrm{g} / \mathrm{mL})$ Vena8Biochips at a shear rate of $1500 \mathrm{~s}^{-1}$ (i) Representative images taken at the end of recording are shown. (ii) Thrombus formation was determined after 4 min by comparing the percentage area covered. (B) Tail bleeding in Pim $1^{+/}$or Pim $1^{\%}$ mice represented as time to cessation of bleeding (s). (C-E) DiOC6 loaded human whole blood was pretreated with vehicle (black) or $100 \mu \mathrm{M}$ AZD1208 (red) for 10 min before perfusion through collagen-coated (100 $\mu \mathrm{g} / \mathrm{mL}$ ) Vena8Biochips at (C) an arterial shear rate of 20 dyn/cm ${ }^{2}$, (D) a pathological shear rate of $135 \mathrm{dyn} / \mathrm{cm}^{2}$, or (E) a venous shear rate of $4.5 \mathrm{dyn} / \mathrm{cm}^{2}$. The concentration of $100 \mu \mathrm{M}$ AZD1208 was chosen because of the reduced bioavailability of AZD1208 in plasma. Thrombus formation was determined after 5 min (pathological shear) or 10 min (arterial and venous shear) by comparing percentage of maximum vehicle-treated fluorescence intensity, which measures both surface area coverage and thrombus size, in the vehicle and treated samples. (i) Representative images taken at the end of recording are shown. (ii) Data expressed as percentage of maximum vehicle-treated fluorescence intensity. (F) Thrombus formation was determined in vivo following ferric chloride-induced injury in mice pretreated for 10 mins with vehicle or $100 \mu \mathrm{M}$ AZD1208. DiOC6 was used to enable visualization of platelets. (i) representative images taken at 0, 300, 600 and $900 \mathrm{~s}$. (ii) Data expressed as time to occlusion (s). (G) Tail bleeding determined as time to cessation of bleeding (s) in mice pretreated with vehicle or $100 \mu$ M AZD1208 for 10 min. Results are mean \pm standard error of mean for $n \geq 3$, $* P \leq 0.05$, $* * P \leq 0.01$ $* * * * P \leq 0.001$ in comparison to vehicle control; where normalized data are shown statistics were performed prior to normalization.

trols (Online Supplementary Figure S6). This suggests that Pim kinase inhibitors inhibit aggregation by reducing both integrin activation and secretion of granule contents.

\section{Pim kinase inhibitors reduce platelet activation to GPVI via reduced TPaR signaling}

TxA2 is synthesized and released following platelet activation by several platelet agonists. It acts as a secondary mediator, boosting platelet responses to other agonists, and is essential for the amplification of platelet activation and thrombus formation. Further investigation of the inhibitory actions of AZD1208 identified significant inhibition of U46619-evoked aggregation with half maximal inhibitory concentration $\left(\mathrm{IC}_{50}\right)$ values $<10 \mu \mathrm{M}$, concentrations similar to those achieved in plasma in patients taking AZD $1208{ }^{24}$ following stimulation by low concentrations of U46619 (0.03-1 $\mu \mathrm{M})$ (Figure 4A). In contrast the inhibitory activity of AZD1208 could be overcome at higher concentrations of U46619 (3 and $10 \mu \mathrm{M}$ ). Collagen-induced platelet activation is known to be dependent on the release of secondary mediators. To test whether the inhibition of collagen-induced platelet aggregation by AZD1208 was a result of reduced activation of the TPaR, platelet aggregation in response to a range of collagen concentrations was measured following treatment with AZD1208 $(10 \mu \mathrm{M})$. We performed the experiments in the presence or absence of indomethacin (10 $\mu \mathrm{M})$, a cyclo-oxygenase (COX) inhibitor that prevents TxA2 synthesis, or a TPaR antagonist GR32191 (100 nM) to investigate whether inhibition was additive. As shown in Figure 4B, both indomethacin and GR32191 caused an inhibition of collagen-induced platelet aggregation, but this was not additive to the inhibition caused by AZD1208, suggesting that AZD1208 shares a common 


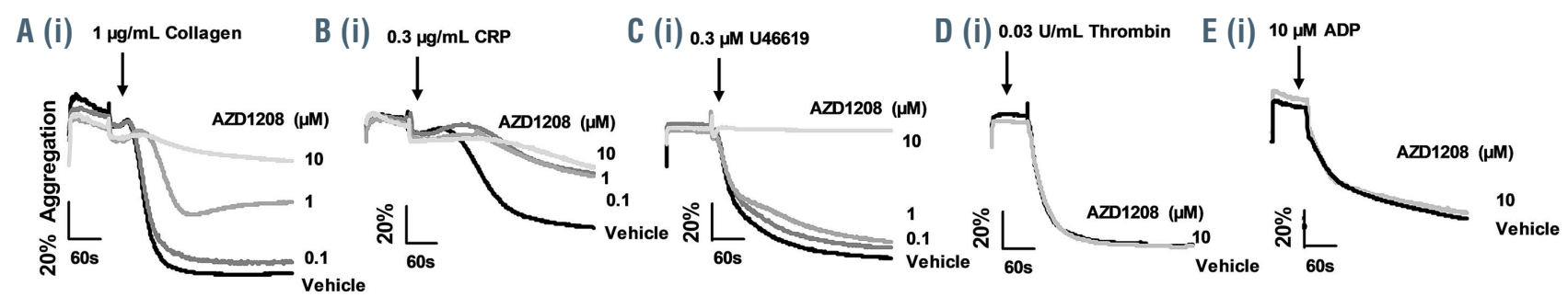

(ii)

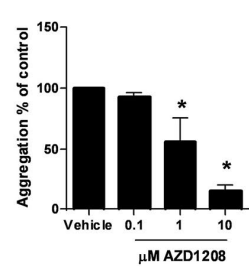

(iii)

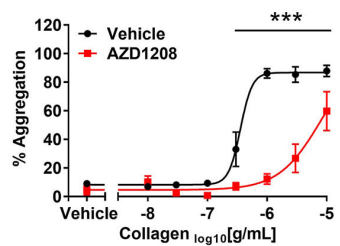

(ii)

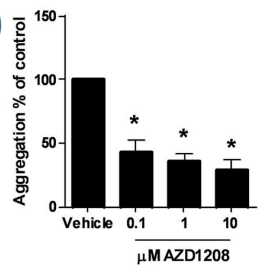

(iii) (ii)

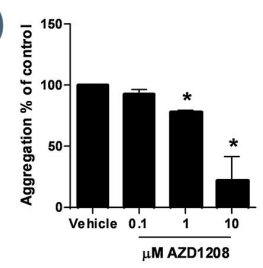

(iii) (ii)

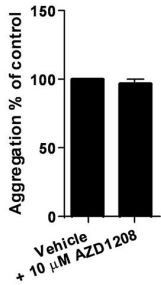

(ii)

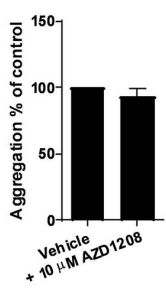

(iii)
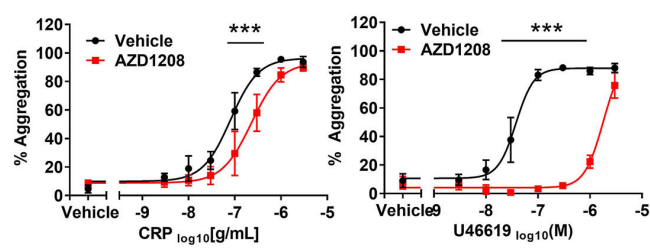

(iii)
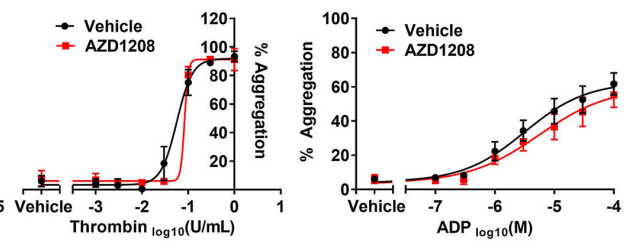

Figure 3. AZD1208 inhibits platelet aggregation. (A-E, i and ii) Washed human platelets were pretreated with increasing concentrations of AZD1208 (0.1, 1, $10 \mu \mathrm{M})$ prior to stimulation with (A) collagen (1 $\mu \mathrm{g} / \mathrm{mL})$, (B) CRP-XL $(0.3 \mu \mathrm{g} / \mathrm{mL}),(\mathrm{C}) \mathrm{U} 46619(0.3 \mu \mathrm{M})$, (D) thrombin $(0.03 \mathrm{U} / \mathrm{mL})$ or $(\mathrm{E}) \mathrm{ADP}(10 \mu \mathrm{M})$ and aggregation $\mathrm{moni}-$ tored using optical light transmission aggregometry. (i) Representative traces and (ii) quantified data are shown. (A-E, iii) Human washed platelets were pretreated

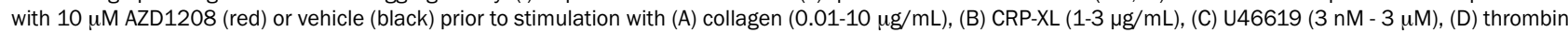
(0.01-1 $\mathrm{U} / \mathrm{mL})$ or (E) ADP (0.1-100 $\mu \mathrm{M})$ and aggregation was monitored after 5 min using an optical light transmission plate-based aggregometry assay; quantified data are shown. Results are mean \pm standard error mean for $n \geq 3, * P \leq 0.05 * * * P \leq 0.005$ in comparison to vehicle control; where normalized data are shown statistics were performed prior to normalization.

TPaR.-dependent mechanism. The inhibition observed in collagen-stimulated platelets is likely due to the loss of TxA2 signaling, indicating that Pim kinase has a positive regulatory role in the regulation of $\mathrm{TP} \alpha \mathrm{R}$ signaling. Similar results were also observed following treatment with structurally unrelated Pim kinase inhibitors SGI1776, PIM-447 (LGH447), SMI-4a and CX6258 in the presence or absence of indomethacin (Online Supplementary Figure S4D-G). In further support of this, we also observed that AZD1208-mediated inhibition of thrombus formation on collagen under flow occurred via a TP $\alpha$ R-dependent mechanism, as indomethacin $(10 \mu \mathrm{M})$ did not cause further inhibition of thrombus formation when combined with AZD1208 treatment (Figure 4C). In support of the effects of AZD1208 being mediated via Pim kinase, and a role for Pim kinase in the regulation of platelet TP $\alpha \mathrm{R}$ signaling, platelets from Pim $1^{-1}$ mice (red) displayed reduced fibrinogen binding, compared to controls (black), following stimulation with U46619 (10 $\mu \mathrm{M})$ or CRP-XL $(10 \mu \mathrm{g} / \mathrm{mL})$ but not following stimulation with thrombin $(0.01 \mathrm{U} / \mathrm{mL})$ (Figure 4D).

\section{Pim kinase inhibitors inhibit platelet function independently of COX1}

The synthesis of TxA2 in platelets is dependent on activation of COX1 following platelet stimulation. To determine whether the inhibitory effects of Pim kinase inhibitors were due to altered COX activity, thromboxane $\mathrm{B} 2$ ( $\mathrm{TxB} 2$ ) levels (a marker of TxA2 release) were determined following stimulation of platelets with arachidonic acid (a direct substrate for COX1 and the TxA2 synthesis pathway) or collagen and compared to the levels following treatment with indomethacin, a COX1 inhibitor, in the presence of the TP $\alpha \mathrm{R}$ antagonist GR32191 to remove secondary TP $\alpha$ R feedback mechanisms. While indomethacin caused almost complete ablation of both collagen- and arachidonic acid-induced platelet TxB2 generation, AZD1208 did not cause any significant alterations in $\mathrm{TxB} 2$ generation indicating that it does not regulate COX1 activity (Figure 5A). In further support of AZD1208 mediating its inhibitory actions via inhibition of TP $\alpha$ R receptor signaling and not inhibition of cyclo-oxygenase activity, while AZD1208 causes inhibition of U46619-mediated platelet aggregation, concentrations of indomethacin that cause ablation of platelet responses to arachidonic acid are unable to inhibit platelet activation by the TP $\alpha$ R agonist U46619 (Figure 5A).

\section{Pim kinase inhibitors reduce signaling events downstream of TP $\alpha R$}

The TP $\alpha$ R receptor is coupled to both $G_{q}$ and $G_{\alpha 13}$ proteins. $G_{q}$ couples the TP $\alpha$ R to phospholipase $C$ which in turn regulates calcium mobilization and the activation of protein kinase $\mathrm{C}(\mathrm{PKC})$, key mediators of granule secretion and activation of integrin $\alpha_{\mathrm{IIb}} \beta_{3} . \mathrm{G}_{\alpha 13}$ regulates the Rho/Rho-kinase signaling pathway which regulates the phosphorylation of myosin IIa and is important for the regulation of cytoskeletal rearrangements and platelet shape change. 
A

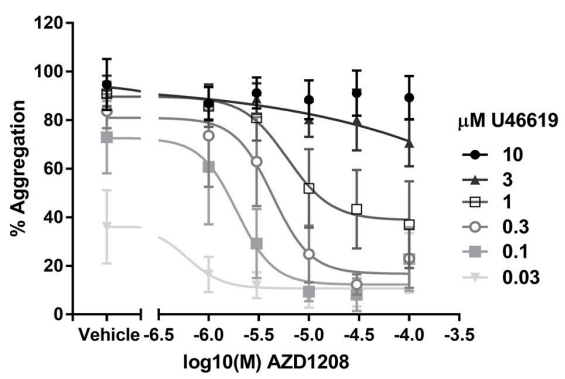

C (i)

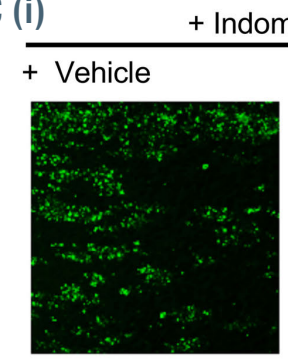

B (i)

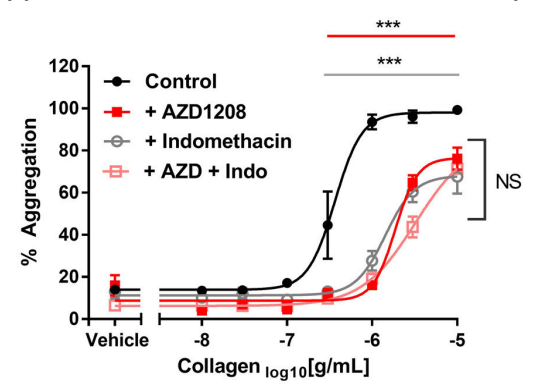

C (ii)

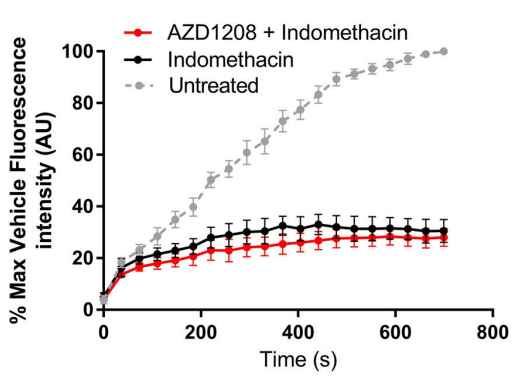

(ii)

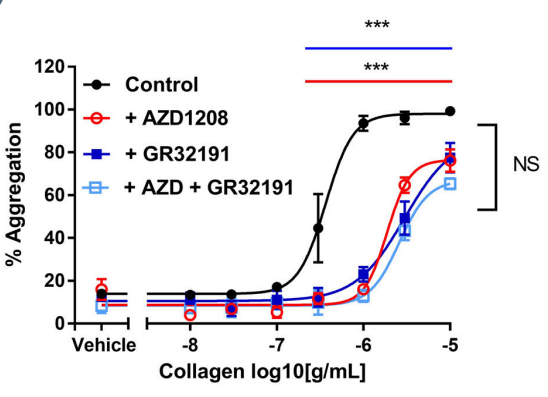

D

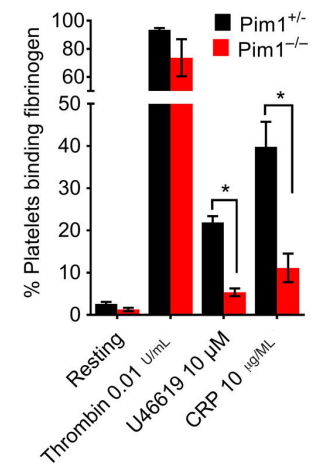

Figure 4. Inhibition of thromboxane A2 signaling underlies inhibition of collagen-induced aggregation and thrombus formation by Pim kinase inhibitors. (A, B) Human washed platelets were treated with $(A)$ increasing concentrations of AZD1208 (1-100 $\mu \mathrm{M})$ or vehicle control prior to stimulation with increasing concentrations of U46619 (0.03-10 $\mu \mathrm{M})$ or (B) $10 \mu \mathrm{M}$ AZD1208 in the presence or absence of (i) indomethacin (10 $\mu \mathrm{M})$ or (ii) the thromboxane $\mathrm{A}_{2}$ receptor antagonist GR32191 $(100 \mathrm{nM})$. Platelet aggregation was monitored after $5 \mathrm{~min}$ of stimulation by collagen $(0.01-10 \mu \mathrm{g} / \mathrm{mL})$ using a $96-$ well plate based aggregometry assay. (C) DiOC6 loaded human whole blood was pretreated with vehicle (black) or $100 \mu \mathrm{M}$ AZD1208 (red), in the presence of $10 \mu \mathrm{M}$ indomethacin for 10 min before perfusion through collagen coated $(100 \mu \mathrm{g} / \mathrm{mL})$ Vena8Biochips at a shear rate of $20 \mathrm{dyn} / \mathrm{cm}^{2}$. Thrombus formation was determined over 10 min by comparing fluorescence intensity in the vehicle and treated samples. (i) Representative images taken at $10 \mathrm{~min}$. (ii) Data expressed as the percentage of maximum fluorescence of vehicle treated cases and normalized to an untreated (no indomethacin treatment) control, where the maximum fluorescence observed in untreated platelets is considered to be $100 \%$ thrombus formation. (D) Fibrinogen binding in washed platelets from control $\left(\right.$ Pim $\left.1^{+/}\right)$or Pim $1^{\%}$ mice was determined following stimulation with thrombin $(0.01 \mathrm{U} / \mathrm{mL}), \mathrm{U} 46619(10 \mu \mathrm{M})$ or CRP $(10 \mu \mathrm{g} / \mathrm{mL})$ and expressed as percentage of positive cells. Results are mean $+\mathrm{standard}$ error of mean for $\mathrm{n} \geq 3$, $* P \leq 0.05$ $\star * * P \leq 0.005$ in comparison to vehicle control; where normalized data are shown, statistics were performed prior to normalization.

To determine whether Pim kinase regulates processes downstream of TP $\alpha$ R coupled G proteins, levels of intracellular calcium, PKC activity and myosin light chain (MLC) phosphorylation were monitored following stimulation with U46619. As shown in figure $5 \mathrm{~B}$, treatment of platelets with AZD1208 caused a significant reduction in calcium mobilization following stimulation with U46619 $(0.3 \mu \mathrm{M})$ compared to vehicle-treated control platelets. In contrast no significant difference in calcium mobilization was observed following stimulation with ADP $(10 \mu \mathrm{M})$ supporting a specific role for Pim kinase in the regulation of TP $\alpha$ R signaling. AZD1208 also caused a reduction both in PKC activity and MLC (S19) phosphorylation compared to vehicle controls following stimulation with U46619 (1 $\mu \mathrm{M})$ (Figure 5C and D). Ga13 is also associated with the regulation of integrin $\alpha_{\mathrm{IIb}} \beta_{3}$ outside in signaling. ${ }^{25}$ Phosphorylation of $Y 773$ on the integrin $\beta 3$ tail which is essential for propagation of outside-in signaling was reduced in U46619 stimulated platelets pretreated with AZD1208 compared to vehicle-treated control platelets (Figure 5E). Taken together these results support a role for Pim kinase in the positive regulation of $G_{q}$ and $G \alpha 13$ signaling downstream of TP $\alpha \mathrm{R}$ activation.

\section{AZD1208 is not a competitive antagonist of the TP $\alpha R$}

As components of both $\mathrm{G}_{\mathrm{q}}$ and $\mathrm{G}_{13}$ signaling, pathways immediately downstream of $\mathrm{TP} \alpha \mathrm{R}$ activation, were found to be inhibited following treatment with AZD1208 we hypothesized that the inhibitor was having direct effect on the function of the TP $\alpha \mathrm{R}$ itself. One potential mechanism of action could be that Pim kinase inhibitors such as AZD1208 act as antagonists of the TP $\alpha R$ and inhibit the $\mathrm{TP} \alpha \mathrm{R}$ directly, independently of Pim kinase. To determine whether AZD1208 acts as a competitive $\mathrm{TP} \alpha \mathrm{R}$ antagonist, platelet aggregation was measured following treatment with increasing concentrations of AZD1208 and stimulation with a range of U46619 concentrations so that the concentration relationship between inhibitor and antagonist could be quantified by Schild analysis. As shown in Figure 6A the inhibitory effect of AZD1208 became saturated by $10 \mu \mathrm{M}$, with higher concentrations $(30,50,100 \mu \mathrm{M})$ unable to achieve greater levels of inhibition. In contrast, increasing concentrations of the competitive TP $\alpha$ antagonist GR32191 (Figure 5) caused non-saturable inhibition of aggregation stimulated by U46619 and generated a linear Schild plot with a pA2 of 8.9 which was consistent with the reported properties of this competitive antagonist acting at the TP $\alpha R{ }^{26}{ }^{26}$ In contrast, the Schild plot for AZD1208 was linear up to a concentration of $10 \mu \mathrm{M}$ at which point the inhibitory effects were saturated and increasing concentrations of AZD1208 no longer altered the apparent $\mathrm{EC}_{50}$ of U46619. These results indicate that the concentrationresponse relationship of GR32191 and U46619 in the 


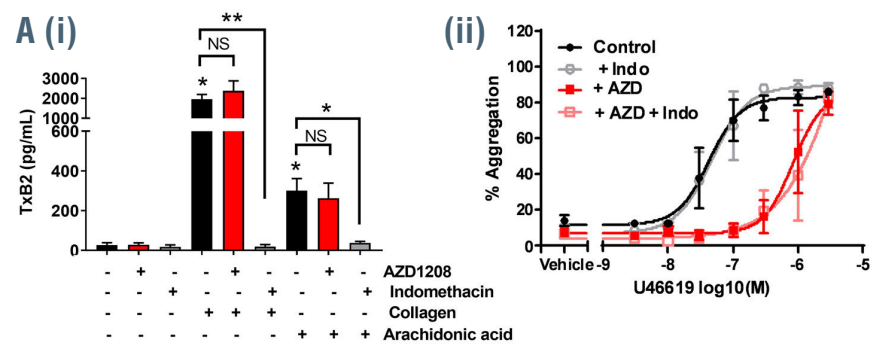

B (i)

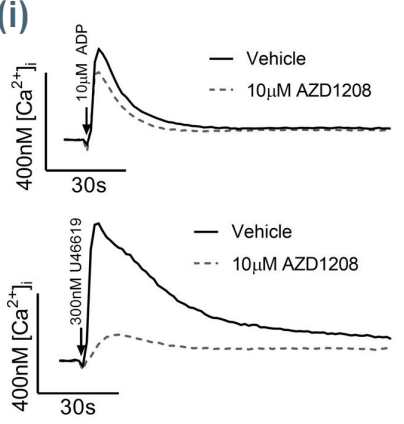

D (i)

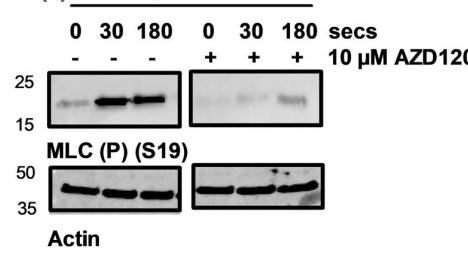

(ii)

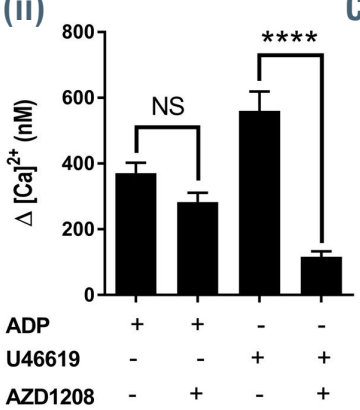

C (i)

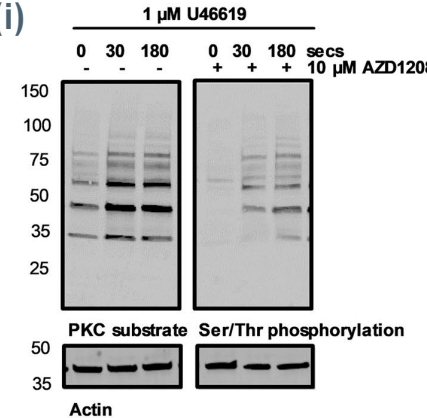

(ii)

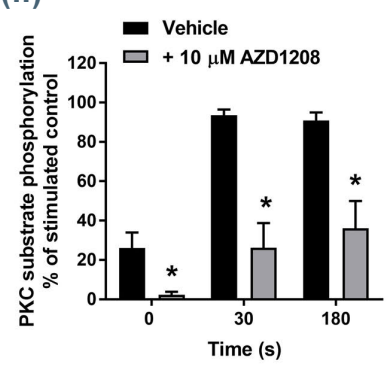

(ii)

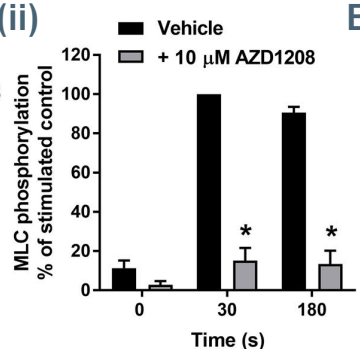

E (i)

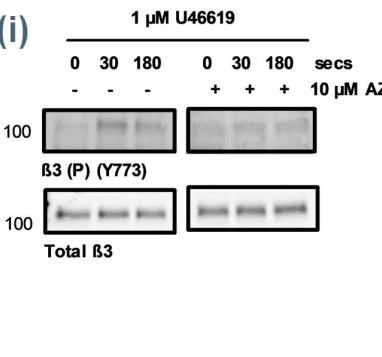

(ii)

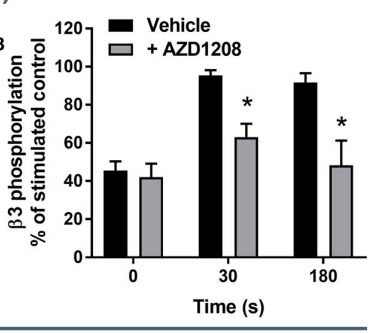

Figure 5. AZD1208 inhibits thromboxane receptor signaling. (A) Resting and stimulated human washed platelets were treated with $10 \mu \mathrm{M}$ AZD1208 for 10 min and stimulated with (i) collagen $(1 \mu \mathrm{g} / \mathrm{mL})$ or arachidonic acid $(1 \mathrm{mM})$ or (ii) U46619 $(0-3 \mu \mathrm{M})$ in the presence and absence of indomethacin (10 $\mu \mathrm{M})$. (i) TxB2 levels (EnzoLife Sciences ELISA) or (ii) aggregation were monitored after 5 min of shaking. (B) Mobilization of intracellular calcium was determined in FURA-2 AM loaded platelets following stimulation with U46619 (300 nM) or ADP $(10 \mu \mathrm{M})$. (i) Representative traces and (ii) quantified data are shown, with data expressed as the change in $\left[\mathrm{Ca}^{2+}\right](\mathrm{nM})$. (C-E) Human platelets were pre-incubated with vehicle or AZD1208 (10 $\left.\mu \mathrm{M}\right)$ for 10 min and stimulated with U46619 (1 $\left.\mu \mathrm{M}\right)$ for $30 \mathrm{~s}$ or 3 min before lysis in SDS Laemmli sample buffer. (C) Protein kinase C (PKC) activity was determined by blotting these samples and using a phospho-site specific antibody (for the PKC substrate recognition sequence) that detects PKC substrate phosphorylation. (D) Myosin light chain (MLC) phosphorylation at Ser19 was determined using a phospho-specific antibody that recognizes the phosphorylated MLC. (E) Phosphorylation of the integrin $\beta 3$ subunit at Y773 was determined using a phospho-specific antibody. Actin was used to confirm equal loading. (i) Representative blots and (ii) quantified data are shown. Levels of total phosphorylation were quantified and expressed as a percentage of the maximum phosphorylation observed in vehicle-treated, stimulated controls. Results are mean + standard error of mean for $n \geq 3$, $* P \leq 0.05$ in comparison to vehicle controls.

aggregation assay was consistent with that of a TP receptor agonist and antagonist competing to bind to the orthosteric site, while the results with AZD1208 do not conform to this model.

\section{AZD1208 alters TP $\alpha$ R receptor surface expression}

It has been described previously that Pim kinase modulates levels of the CXCR4 receptor at the surface of chronic lymphocytic leukemia cells. ${ }^{18,19}$ We hypothesized that Pim kinase inhibitors could modulate TP $\alpha$ R function via a similar mechanism in platelets and measured expression levels of TP $\alpha$ R following treatment with AZD1208 using flow cytometry to investigate this further. A TP $\alpha$ R antibody that recognizes the $\mathrm{N}$-terminal (extracellular) region of the TPaR was used to determine surface expression levels of TP $\alpha \mathrm{R}$ on platelets (Figure 6C). As previously described, ${ }^{27}$ stimulation of platelets with U46619 was associated with a reduction in cell surface levels of TP $\alpha$, compared to the levels on unstimulated platelets, due to receptor internalization. Resting platelets treated with AZD1208 $(10 \mu \mathrm{M})$ showed reduced surface levels of the $\mathrm{TP} \alpha \mathrm{R}$ receptor compared to the levels in vehicle-treated controls with total levels of $\mathrm{TP} \alpha \mathrm{R}$ unaffected by AZD1208 treatment. U46619- (1 $\mu \mathrm{M})$ stimulated platelets pretreated with AZD1208 also showed reduced surface expression levels of $\mathrm{TP} \alpha \mathrm{R}$ compared to both those of vehicle-treated controls and of platelets treated with U46619 only. These findings indicate that reduced U46619 signaling following treatment with AZD1208 is linked to reduced surface expression levels of TP $\alpha$ R.

\section{AZD1208 inhibits CXCR4 signaling in human platelets}

CXCR4 is expressed in platelets and is able to signal following stimulation with its ligand SDF-1 $\alpha{ }^{28-30}$ To determine whether inhibition of Pim kinase alters CXCR4 signaling in human platelets, aggregometry following stimulation with SDF-1 $\alpha(200 \mathrm{ng} / \mathrm{mL})$ was performed in vehicle- and AZD1208-treated human platelet-rich plasma. SDF- $1 \alpha$ caused a modest level of platelet aggregation $(\sim 50 \%)$ in vehicle-treated platelets which was significantly reduced in AZD1208- $(100 \mu \mathrm{M})$ treated samples ( 20\% aggregation) (Figure 6D). These observations indicate that in addition to regulation of the TP $\alpha$ R, Pim kinase also regulates platelet CXCR4 receptor function. 
A (i)

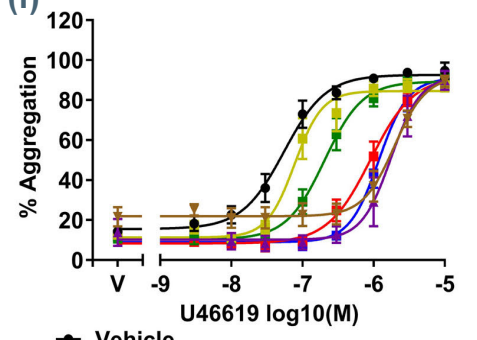

$\rightarrow$ Vehicle

$-+1 \mu \mathrm{M}$ AZD1208 $-+30 \mu \mathrm{M}$ AZD1208

$-+3 \mu \mathrm{M}$ AZD1208 $-+50 \mu \mathrm{M}$ AZD1208

$++10 \mu \mathrm{M}$ AZD1208 $++100 \mu \mathrm{M}$ AZD1208 (ii) B (i)

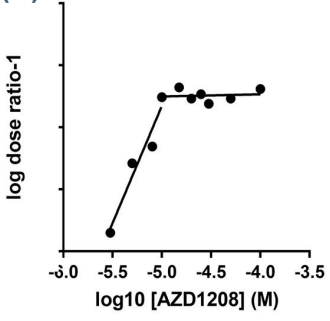

$\log 10$ [AZD1208] (M)

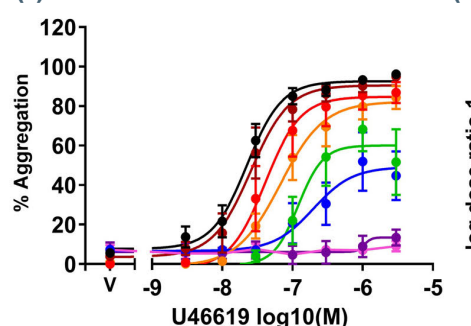

$\rightarrow$ Vehicle $\rightarrow 5$ nM GR32191

$\rightarrow 1$ nM GR32191 $\rightarrow 10$ nM GR32191

$\rightarrow 2$ nM GR32191 $\rightarrow 30$ nM GR32191

$\rightarrow 3$ nM GR32191 $\rightarrow 100$ nM GR32191 (ii)

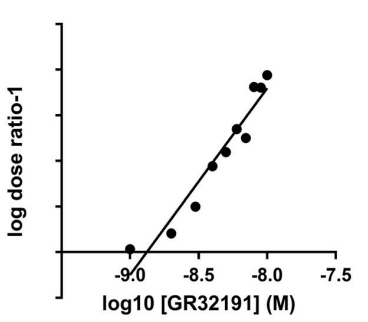

C (i)

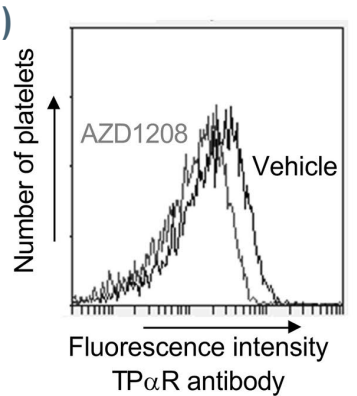

D (i)

$200 \mathrm{ng} / \mathrm{mL}$ SDF-1 $\alpha$

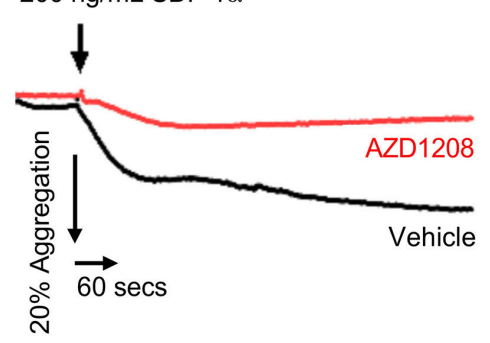

(ii)

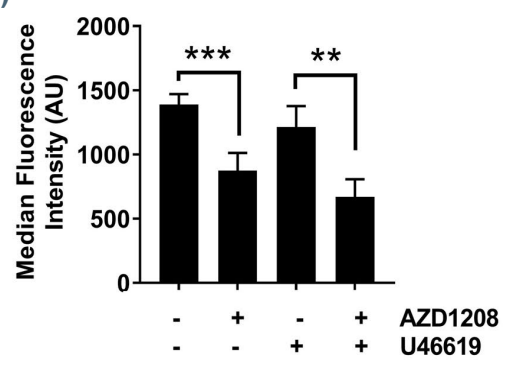

(ii) (iii)

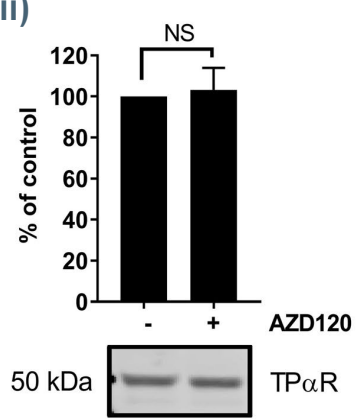

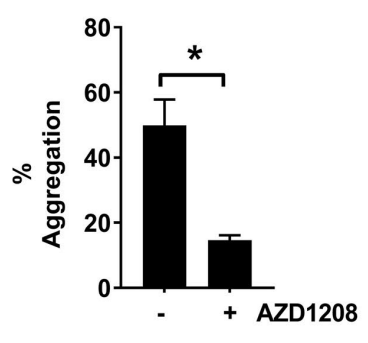

Figure 6. AZD1208 reduces TP $\alpha R$ surface expression and signaling and does not act as a competitive antagonist of the TP $\alpha R$. (A, B) Human washed platelets were pre-treated with: (A) AZD1208 (1, 3, 10, 30, 50 and $100 \mu \mathrm{M})$ or (B) GR32191 (1, 2, 3, 5, 10, 30, $100 \mathrm{nM})$ prior to stimulation with U46619 (3 nM-3 $\mu$ M) and aggregation was monitored after 5 min using an optical light transmission plate-based aggregometry assay. Quantified data are shown. (i) Percentage aggregation. (ii) $\mathrm{EC}_{50}$ values from the aggregation dose-response curves determined following incubation with AZD1208 were used to plot a Schild regression plot to determine whether AZD1208 acts as an antagonist for the TxA2 receptor. (C) Platelets were treated with AZD1208 (10 $\mu$ M; 10 mins) or vehicle control. Surface expression of TPaR was assessed using an antibody that recognizes the extracellular portion of the TP $\alpha$ R and detected by flow cytometry. Samples were diluted in HBS and not fixed to avoid disruption of the membrane. Anti-DOK6 antibody was included as a negative control. (i) A representative histogram from the flow cytometer. (ii) Data are expressed as median fluorescent intensity (MFI). (iii) Total cellular TP $\alpha R$ was detected by western blotting. (D) Human platelet-rich plasma was pretreated with AZD1208 (100 $\mu \mathrm{M})$ or vehicle, as a control, for 10 min prior to stimulation with SDF-1 $\alpha(200 \mathrm{ng} / \mathrm{mL})$ and aggregation was monitored using optical light transmission aggregometry for 5 min. (i) Representative trace and (ii) quantified data are shown. Results are mean + standard error of mean for $n \geq 3, * P \leq 0.05, * * P \leq 0.01$, $* * * P \leq 0.005$ in comparison to vehicle-treated control; where normalized data are shown, statistics were performed prior to normalization.

\section{Discussion}

Development of kinase inhibitors as potential therapeutics for solid tumors and hematologic malignancies has been fueled by the recent successes of kinase inhibitor therapy for cancers. ${ }^{1,2,31,32}$ Pim kinase is known to enhance cancer progression and drug resistance, and loss of all three Pim kinase isoforms does not affect embryo viability, indicating that inhibition of Pim activity is likely to be tolerable. . $^{1,11,33}$ In addition to its well-established role in the regulation of cycle progression and prevention of cellular apoptosis, ${ }^{3-6,23}$ Pim kinase has also been shown to play roles in cell migration, potentially contributing to metastasis and cell invasion ${ }^{18,19}$ and is also implicated in drug resistance through activation of multidrug resistance transporters. ${ }^{7-9} \mathrm{Pim}$ kinase is therefore seen as a promising potential drug target.
Pim kinases have been shown to be highly expressed in hematopoietic cells with important roles in the development and differentiation of megakaryocytes ${ }^{10}$ and platelets. ${ }^{11,15}$ Deletion of Pim-1 alone has no effect on the hematopoietic system, ${ }^{16}$ possibly indicating a level of redundancy between the Pim kinase family members. Kinases, however, often have broad expression profiles across several different cell types, which increases the risk of kinase inhibitors having unwanted side effects. Platelets in particular rely heavily on kinase-driven signaling cascades to enable them to function effectively in response to vascular damage. Several kinase inhibitors have been reported that affect the ability of platelets to activate and are associated with an increased risk of bleeding. ${ }^{34-36}$

Western blot analysis identified expression of both the 
$44 \mathrm{kDa}$ and $32 \mathrm{kDa}$ variants of Pim-1 kinase in human and mouse platelets. While Pim-2 and Pim-3 were not identified in our assays, expression of either paralog in human and mouse platelets cannot be ruled out. Comparison of thrombus formation on collagen under flow in vitro established that platelets from Pim-1-deficient mice showed significant attenuation in comparison to that in wild-type controls, highlighting a role for Pim1 kinase in the regulation of platelet function and thrombus formation under arterial flow on collagen. Despite the reduction in thrombotic potential, deletion of Pim-1 was not associated with altered hemostasis, indicating that drugs targeting Pim kinase activity could offer an antithrombotic therapeutic strategy that is not associated with the increased bleeding risk usually observed with other antiplatelet agents.

In support of the antithrombotic potential of Pim kinase inhibitors we determined that several structurally different Pim kinase inhibitors, AZD1208, PIM-447, SGI1776, SMI-4a and CX6258, which are pan-Pim kinase inhibitors that target all three Pim kinases, all caused inhibition of platelet functional responses, including aggregation in response to GPVI agonists collagen and CRP-XL, CXCR4 ligand SDF-1 $\alpha$ (CXCL12) and TxA2 mimetic U46619, but not to other GPCR agonists including thrombin, TRAP6 and ADP, with an inhibitory profile similar to that observed by Lordkipanidzé et al. in a patient with a mutation in the TP receptor ${ }^{27,37}$ Furthermore inhibition of collagen-induced platelet responses was found to be due to an inhibition of TP $\alpha$ R signaling, as the level of platelet aggregation observed in the presence of indomethacin or the TP $\alpha R$ antagonist GR32191 was not further decreased following treatment with AZD1208 $(10 \mu \mathrm{M})$. Similarly to the reduced thrombus formation observed in whole blood from Pim-1-deficient mice, AZD1208 caused significant attenuation of thrombus formation on collagen under flow in vitro at both arterial and pathological shear rates and a dramatic inhibition of thrombus formation in vivo (Figure 2). Interestingly, however, no effect on platelet adhesion and thrombus formation at venous flow rates was observed following treatment with AZD1208; this, combined with the lack of effect on bleeding in mice following damage to the tail vein, suggests that although Pim kinase inhibition or deficiency reduces thrombus formation under high arterial shear, this does not alter thrombus formation or hemostasis at venous or low shear. This absence of effect is likely due to the lack of inhibition of PAR or P2Y receptor-mediated platelet activation by Pim kinase inhibitors. Previous studies have shown that while GPVI deficiency or inhibition has varying effects in tail bleeding assays, ${ }^{38,39}$ PAR or P2Y12 deficiency or P2Y1 inhibition results in significant increases in tail bleeding and alteration of hemostasis in mice. ${ }^{39-41} \mathrm{As}$ initial adhesion to collagen is unaffected following treatment with AZD1208, maintenance of PAR and P2Y receptor responses may compensate for the lack of TP receptor signaling, allowing for normal hemostasis. The lack of bleeding effect following treatment with AZD1208 is consistent with the lack of reported bleeding-related adverse effects in patients in a recent phase I clinical study investigating the efficacy of AZD1208 in solid and hematologic cancers. ${ }^{24}$ This provides further evidence that Pim kinase inhibitors may not be associated with drug-induced platelet dysfunction-related bleeding events and points to future use of Pim kinase inhibitors as a possible treatment strategy for individuals with increased risk of cardiovascular disease and atherosclerosis, conditions associated with pathological shear rates.

Investigation into how Pim kinases elicit their inhibitory effects on TPaR signaling, revealed that AZD1208 inhibited TPaR downstream signaling events, pointing to upstream regulation of $\mathrm{TP} \alpha \mathrm{R}$ signaling most likely via direct regulation of the TPaR. It has previously been described that Pim-1 kinase regulates CXCR4 activity in Jurkat and chronic lymphocytic leukemia cells via regulation of surface expression levels of the receptor. ${ }^{18,19}$ Inhibition or deletion of Pim kinase reduces surface expression levels of CXCR4 and inhibits CXCL12/SDF-1 signaling. ${ }^{29,30}$ Similarly, in our study we identified reduced surface expression levels of TPaR in platelets following treatment with AZD1208 compared to the levels in vehicle-treated controls.

The TPaR signaling pathway is a key target to reduce cardiovascular disease-related thrombotic events and inflammation in patients. Despite widespread use, currently available GPCR-targeted therapies are associated with variable outcomes and adverse side effects in patients. Aspirin is the 'gold standard' antiplatelet agent for the prevention of arterial thrombosis. Aspirin targets platelet TP $\alpha$ R signaling via an indirect route, by inhibiting COX1, the enzyme that controls synthesis of TxA2. Aspirin, however, has dose-limiting off-target effects on $\mathrm{COX} 2$, an enzyme involved in synthesis of endogenous inhibitors of platelet function that can increase the risk of thrombosis when repressed. Aspirin is also less effective in patients suffering from diabetes, hypertension and obesity, and is associated with an increased risk of severe bleeding ${ }^{42}$ with one recent meta-analyses suggesting that in low-risk individuals the harms of aspirin outweigh the cardiovascular benefits. ${ }^{43-45}$ Our findings suggest that Pim kinases may be a safer target to control thrombosis.

The mechanism underlying the regulation of $T P \alpha R$ signaling by Pim-1 kinase requires further investigation. In other cell types the $44 \mathrm{kDa}$ variant of Pim-1 kinase, Pim$1 \mathrm{~L}$ is localized to the plasma membrane and associated with the phosphorylation and regulation of several membrane proteins, while the smaller $32 \mathrm{kDa}$ variant Pim-1S predominantly localizes to the cytosol and nucleus. ${ }^{7,46}$ One possibility is that Pim kinase phosphorylates the TP $\alpha$ R. controlling its surface expression levels, similar to the mechanism observed for CXCR4 in chronic lymphocytic leukemia cells. Sequence alignments of the Pim kinase substrate recognition sequence have identified four putative Pim kinase phosphorylation sites within the $\mathrm{TP} \alpha \mathrm{R}$ sequence, including one within the first intracellular loop, a region that has previously been shown to be associated with TPaR surface expression and receptor function. ${ }^{27}$ Pim kinase inhibition may therefore disrupt phosphorylation of the receptor and reduce surface expression via increasing its internalization or preventing the dynamic process of receptor recycling to the surface. It is also possible that Pim kinase does not phosphorylate the receptor directly and instead orchestrates interactions with other proteins that regulate receptor surface expression. ${ }^{18,19}$

This work identifies a novel, Pim kinase-dependent regulatory mechanism for the $\mathrm{TP} \alpha \mathrm{R}$ and represents a new targeting strategy that is independent of COX1 inhibition or direct antagonism of the TPaR that, while reducing thrombosis, does not increase the risk of bleeding. 


\section{Disclosures}

No conflicts of interest to disclose.

\section{Contributions}

$A J U$ designed the research, performed experiments, analyzed results and wrote the paper; $A P B, T S, R S G, N E, C D, A S, N K$, $P J V, L H, R R, S J, S M$ and WC performed experiments and analyzed results; HF and JMG designed the research and wrote the paper.

\section{Acknowledgments}

The authors would like to thank Gemma Little, Joanne
Mitchell and Mike Fry, University of Reading, for their help with the work and preparation of this manuscript.

\section{Funding}

This work was supported by the British Heart Foundation programme grant RG/15/2/31224 (to JMG), British Heart Foundation project grant PG/2019/34798 (to AJU), National Institutes of Health RO1 grants HL126743 (to HF) and AI125741 (to WC), the Centre for Biosciences, Manchester Metropolitan University and Manchester Metropolitan University RKE Internal Funding grant 343846 (to AU)..

\section{References}

1. Pogacic V, Bullock AN, Fedorov O, et al. Structural analysis identifies imidazo[1,2b]pyridazines as PIM kinase inhibitors with in vitro antileukemic activity. Cancer Res. 2007;67(14):6916-6924.

2. Shah N, Pang B, Yeoh KG, et al. Potential roles for the PIM1 kinase in human cancer a molecular and therapeutic appraisal. Eur J Cancer. 2008:44(15):2144-2151.

3. Bachmann M, Moroy T. The serine/threonine kinase Pim-1. Int J Biochem Cell Biol. 2005;37(4):726-730

4. Bachmann M, Kosan C, Xing PX, Montenarh M, Hoffmann I, Moroy T. The oncogenic serine/threonine kinase Pim-1 directly phosphorylates and activates the G2/M specific phosphatase Cdc25C. Int J Biochem Cell Biol. 2006:38(3):430-443.

5. Macdonald A, Campbell DG, Toth $\mathrm{R}$, McLauchlan H, Hastie CJ, Arthur JS. Pim kinases phosphorylate multiple sites on Bad and promote 14-3-3 binding and dissociation from Bcl-XL. BMC Cell Biol. 2006;7:1.

6. Aho TL, Sandholm J, Peltola KJ, Mankonen HP, Lilly M, Koskinen PJ. Pim-1 kinase promotes inactivation of the pro-apoptotic Bad protein by phosphorylating it on the Ser112 gatekeeper site. FEBS Lett. 2004;571(13):43-49

7. Xie Y, Xu K, Linn DE, et al. The 44-kDa Pim-1 kinase phosphorylates BCRP/ABCG2 and thereby promotes its multimerization and drug-resistant activity in human prostate cancer cells. J Biol Chem. 2008;283(6):3349-3356.

8. Darby RA, Unsworth A, Knapp S, Kerr ID, Callaghan R. Overcoming ABCG2-mediated drug resistance with imidazo-[1,2-b]pyridazine-based Pim1 kinase inhibitors. Cancer Chemother Pharmacol. 2015; 76(4):853-864.

9. Xie Y, Burcu M, Linn DE, Qiu Y, Baer MR Pim-1 kinase protects $\mathrm{P}$-glycoprotein from degradation and enables its glycosylation and cell surface expression. Mol Pharmacol. 2010;78(2):310-318.

10. Mikkers H, Nawijn M, Allen J, et al. Mice deficient for all PIM kinases display reduced body size and impaired responses to hematopoietic growth factors. Mol Cell Biol. 2004;24(13):6104-6115

11. An N, Kraft AS, Kang Y. Abnormal hematopoietic phenotypes in Pim kinase triple knockout mice. J Hematol Oncol. 2013;6:12.

12. Senis YA, Tomlinson MG, Garcia A, et al. A comprehensive proteomics and genomics analysis reveals novel transmembrane proteins in human platelets and mouse megakaryocytes including G6b-B, a novel immunoreceptor tyrosine-based inhibitory motif protein. Mol Cell Proteomics. 2007;6(3):548-564.

13. Weyrich AS, Zimmerman GA. Evaluating the relevance of the platelet transcriptome. Blood. 2003;102(4):1550-1551.

14. Rowley JW, Oler AJ, Tolley ND, et al. Genome-wide RNA-seq analysis of human and mouse platelet transcriptomes. Blood. 2011;118(14):e101-111

15. An N, Lin YW, Mahajan S, et al. Pim1 serine/threonine kinase regulates the number and functions of murine hematopoietic stem cells. Stem Cells. 2013;31(6):12021212.

16. Laird PW, van der Lugt NM, Clarke A, et al. In vivo analysis of Pim-1 deficiency. Nucleic Acids Res. 1993;21(20):4750-4755.

17. Li D, D'Angelo L, Chavez M, Woulfe DS. Arrestin-2 differentially regulates PAR4 and ADP receptor signaling in platelets. J Biol Chem. 2011;286(5):3805-3814.

18. Grundler R, Brault L, Gasser C, et al. Dissection of PIM serine/threonine kinases in FLT3-ITD-induced leukemogenesis reveals PIM1 as regulator of CXCL12CXCR4-mediated homing and migration. J Exp Med. 2009;206(9):1957-1970.

19. Decker S, Finter J, Forde AJ, et al. PIM kinases are essential for chronic lymphocytic leukemia cell survival (PIM2/3) and CXCR4-mediated microenvironmental interactions (PIM1). Mol Cancer Ther. 2014;13(5):1231-1245.

20. Watkins NA, Gusnanto A, de Bono B, et al. A HaemAtlas: characterizing gene expression in differentiated human blood cells. Blood. 2009;113(19):e1-9.

21. Simon LM, Edelstein LC, Nagalla S, et al. Human platelet microRNA-mRNA networks associated with age and gender revealed by integrated plateletomics. Blood. 2014;123(16):e37-45.

22. Lin YW, Beharry ZM, Hill EG, et al. A small molecule inhibitor of Pim protein kinases blocks the growth of precursor T-cell lymphoblastic leukemia/lymphoma. Blood. 2010;115(4):824-833.

23. Yan B, Zemskova M, Holder S, et al. The PIM-2 kinase phosphorylates BAD on serine 112 and reverses BAD-induced cell death. J Biol Chem. 2003;278(46):4535845367.

24. Cortes J, Tamura K, DeAngelo DJ, et al. Phase I studies of AZD1208, a proviral integration Moloney virus kinase inhibitor in solid and haematological cancers. Br J Cancer. 2018;118(11):1425-1433.

25. Gong H, Shen B, Flevaris P, et al. G protein subunit Galpha13 binds to integrin alphaIIbbeta3 and mediates integrin "outside-in" signaling. Science. 2010;
327(5963):340-343

26. Lumley P, White BP, Humphrey PP. GR32191, a highly potent and specific thromboxane A2 receptor blocking drug on platelets and vascular and airways smooth muscle in vitro. $\mathrm{Br} J$ Pharmacol. 1989;97(3):783-794.

27. Nisar SP, Lordkipanidze M, Jones ML, et al A novel thromboxane A2 receptor N42S variant results in reduced surface expression and platelet dysfunction. Thromb Haemost. 2014;111(5):923-932.

28. Akbiyik F, Ray DM, Gettings KF, Blumberg N, Francis CW, Phipps RP. Human bone marrow megakaryocytes and platelets express PPARgamma, and PPARgamma agonists blunt platelet release of CD40 ligand and thromboxanes. Blood. 2004; 104(5):1361-1368.

29. Walsh TG, Harper MT, Poole AW. SDF1 alpha is a novel autocrine activator of platelets operating through its receptor CXCR4. Cell Signal. 2015;27(1):37-46.

30. Clemetson KJ, Clemetson JM, Proudfoot AE, Power CA, Baggiolini M, Wells TN. Functional expression of CCR1, CCR3, CCR4, and CXCR4 chemokine receptors on human platelets. Blood. 2000; 96(13):4046-4054.

31. Keeton EK, McEachern K, Dillman KS, et al AZD1208, a potent and selective pan-Pim kinase inhibitor, demonstrates efficacy in preclinical models of acute myeloid leukemia. Blood. 2014;123(6):905-913.

32. Kirschner AN, Wang J, van der Meer R, et al. PIM kinase inhibitor AZD1208 for treatment of MYC-driven prostate cancer. J Natl Cancer Inst. 2015;107(2):dju407.

33. Din S, Konstandin MH, Johnson B, et al. Metabolic dysfunction consistent with premature aging results from deletion of Pim kinases. Circ Res. 2014;115(3):376-387.

34. Bye AP, Unsworth AJ, Vaiyapuri S, Stainer AR, Fry MJ, Gibbins JM. Ibrutinib inhibits platelet integrin alphaIIbbeta3 outside-in signaling and thrombus stability but not adhesion to collagen. Arterioscler Thromb Vasc Biol. 2015;35(11):2326-2335

35. Gratacap MP, Martin V, Valera MC, et al. The new tyrosine-kinase inhibitor and anticancer drug dasatinib reversibly affects platelet activation in vitro and in vivo. Blood. 2009;114(9):1884-1892.

36. Levade M, Severin S, Gratacap MP, Ysebaert L, Payrastre B. Targeting kinases in cancer therapies: adverse effects on blood platelets. Curr Pharm Des. 2016; 22 (16):2315-2322

37. Lordkipanidze M, Lowe GC, Kirkby NS, et al. Characterization of multiple platelet activation pathways in patients with bleeding as a high-throughput screening option: use of 96-well Optimul assay. Blood. 
2014;123(8):e11-22.

38. Nieswandt B, Watson SP. Platelet-collagen interaction: is GPVI the central receptor? Blood. 2003;102(2):449-461.

39. Bynagari-Settipalli YS, Cornelissen I, Palmer D, et al. Redundancy and interaction of thrombin- and collagen-mediated platelet activation in tail bleeding and carotid thrombosis in mice. Arterioscler Thromb Vasc Biol. 2014;34(12):2563-2569.

40. Dorsam RT, Kunapuli SP. Central role of the P2Y12 receptor in platelet activation. J Clin Invest. 2004;113(3):340-345.

41. Karim ZA, Vemana HP, Alshbool FZ, et al.
Characterization of a novel function-blocking antibody targeted against the platelet P2Y1 receptor. Arterioscler Thromb Vasc Biol. 2015;35(3):637-644.

42. Hankey GJ, Eikelboom JW. Aspirin resistance. Lancet. 2006;367(9510):606-617.

43. Warner TD, Nylander S, Whatling C. Antiplatelet therapy: cyclo-oxygenase inhibition and the use of aspirin with particular regard to dual anti-platelet therapy. $\mathrm{Br} \mathrm{J}$ Clin Pharmacol. 2011;72(4):619-633.

44. Desborough MJR, Keeling DM. The aspirin story - from willow to wonder drug. Br J Haematol. 2017;177(5):674-683.
45. Antithrombotic Trialists (ATT) Collaboration; Baigent C, Blackwell L, Collins R, et al. Aspirin in the primary and secondary prevention of vascular disease: collaborative meta-analysis of individual participant data from randomised trials. Lancet. 2009;373(9678):1849-1860.

46. Xie Y, Xu K, Dai B, et al. The 44 kDa Pim1 kinase directly interacts with tyrosine kinase Etk/BMX and protects human prostate cancer cells from apoptosis induced by chemotherapeutic drugs. Oncogene. 2006;25(1):70-78. 